\title{
Abdominal pain: a survey of clinically important outcomes for future research
}

\author{
Angela M. Mills, MD; Anthony J. Dean, MD; Judd E. Hollander, MD; Esther H. Chen, MD
}

\section{ABSTRACT}

Objective: We aimed to use the consensus opinion of a group of expert emergency physicians to derive a set of emergency diagnoses for acute abdominal pain that might be used as clinically significant outcomes for future research.

Methods: We conducted a cross-sectional survey of a convenience sample of emergency physicians with expertise in abdominal pain. These experts were authors of textbook chapters, peer-reviewed original research with a focus on abdominal pain or widely published clinical guidelines. Respondents were asked to categorize 50 possible diagnoses of acute abdominal pain into 1 of 3 categories: 1) unacceptable not to diagnose on the first emergency department (ED) visit; 2) although optimal to diagnose on first visit, failure to diagnose would not be expected to have serious adverse consequences provided the patient had follow-up within the next 2-7 days; 3) if not diagnosed during the first visit, unlikely to cause long-term risk to the patient provided the patient had follow-up within the next 1-2 months. Standard descriptive statistical analysis was used to summarize survey data.

Results: Thirty emergency physicians completed the survey. Of 50 total diagnoses, 16 were categorized as "unacceptable not to diagnose in the ED" with greater than $85 \%$ agreement, and 12 were categorized as "acceptable not to diagnose in the ED" with greater than $85 \%$ agreement.

Conclusion: Our study identifies a set of abdominal pain conditions considered by expert emergency physicians to be clinically important to diagnose during the initial ED visit. These diseases may be used as "clinically significant" outcomes for future research on abdominal pain.

\section{Keywords: abdominal pain, emergency department}

\section{RÉSUMÉ}

Objectif : Nous avons cherché à obtenir l'opinion consensuelle d'un groupe de médecins d'urgence experts en vue d'établir un ensemble de diagnostics en urgence pour des douleurs abdominales aiguës qui pourraient servir de résultats cliniquement significatifs pour de futures recherches.
Méthodes : Nous avons réalisé une enquête transversale d'un échantillon de commodité de médecins d'urgence ayant une expertise en douleur abdominale. Ces médecins experts étaient des auteurs de chapitres de manuels, de recherche originale portant principalement sur la douleur abdominale et critiquée par des pairs ou de guides de pratique clinique à grande diffusion. Nous avons demandé aux répondants de classer les 50 diagnostics possibles de douleur abdominale aiguë dans 1 des 3 catégories suivantes : 1) inacceptable de ne pas poser le diagnostic lors de la première visite à l'urgence; 2) quoiqu'il soit idéal de poser le diagnostic lors de la première visite à l'urgence, l'absence de diagnostic ne devrait pas avoir de conséquences néfastes à condition que le patient fasse une visite de suivi dans les 2 à 7 jours suivants; 3) si le diagnostic n'est pas posé lors de la première visite à l'urgence, non susceptible d'entraîner des risques à long terme pour le patient à condition qu'il fasse une visite de suivi 1 à 2 mois plus tard. Nous avons utilisé des analyses statistiques descriptives pour résumer les données de l'étude.

Résultats : Trente médecins d'urgence ont rempli le questionnaire. Parmi les 50 diagnostics, 16 ont été classés comme " inacceptable de ne pas poser le diagnostic à l'urgence " et plus de $85 \%$ des répondants étaient d'accord; 12 ont été classés comme " acceptable de ne pas poser le diagnostic à l'urgence " et plus de $85 \%$ des répondants étaient d'accord.

Conclusion : Notre étude détermine un ensemble des pathologies des douleurs abdominales analysées par des médecins d'urgence experts pour lesquelles il est cliniquement significatif de poser un diagnostic lors de la première visite à I'urgence. Ces maladies peuvent servir de résultats " cliniquement significatifs " pour les recherches futures sur la douleur abdominale.

\section{INTRODUCTION}

Abdominal pain is the most common presenting symptom of adult patients in the emergency department (ED), accounting for more than 8 million annual visits in 2006 in the United States. ${ }^{1}$ The clinical assessment of acute

From the Department of Emergency Medicine, University of Pennsylvania, Philadelphia, Pa.

Submitted Sep. 23, 2009; Revised Nov. 24, 2009, Jan. 4, 2010; Accepted Jan. 8, 2010

This article has been peer reviewed.

CJEM 2010;12(6):485-90 
nontraumatic abdominal pain is challenging because its causes are broad, ranging from minor, self-limiting conditions to catastrophic, life-threatening diseases. Patients often have atypical historical and physical examination findings. To avoid missing life-threatening conditions, clinicians rely heavily on diagnostic testing. With an increasing array of available tests, the ED evaluation of patients with undifferentiated abdominal pain is increasingly complex, time-consuming and costly. With the increase in imaging options comes new complications, in particular the long-term consequences of recurrent radiation exposure. ${ }^{2}$

Currently, there are no established practice guidelines or decision rules defining standards for evaluating undifferentiated acute abdominal pain; instead, many studies focus on specific disease processes. ${ }^{3}$ The challenge of developing a set of evidence-based guidelines or conducting research focusing on the evaluation of abdominal pain may be partly due to the absence of widely accepted outcomes that could be used to measure the effectiveness of diagnostic interventions. The development of outcomes for abdominal pain research presents several challenges. For example, studies of risk stratification or diagnostic strategies to identify cardiac ischemia as the cause of chest pain use unambiguous, reliable outcomes such as "30-day death, acute myocardial infarction or revascularization. ${ }^{\prime, 5}$ In contrast, the sequellae of misdiagnosed abdominal pain are too varied to permit a similar formulation of outcomes. In fact, failure to identify the etiology of abdominal pain may result in other abdominal morbidity (e.g., recurrent small bowel obstruction), damage to extra-abdominal organs or systemic illness (e.g., septic shock).

The key to conducting research focused on abdominal pain is to first define a set of meaningful "end points." Such a strategy was used to develop the Ottawa Knee Rules $^{6}$ and the Canadian C-spine Rule, ${ }^{7}$ guidelines for diagnostic testing for which a set of clinically important diagnoses or outcomes were initially developed by a consensus of experts. As there is no similar set of meaningful end points for the ED evaluation of abdominal pain, we sought to derive a series of clinically important outcomes by a consensus opinion of expert emergency physicians.

\section{METHODS}

\section{Study design and population}

We performed a cross-sectional survey of a convenience sample of physicians who were determined by consensus among the authors to have an expertise in the emergency evaluation of abdominal pain. This determination was made after review of chapters on abdominal diseases in emergency medicine textbooks and peer-reviewed journals with representatives from each of the major geographic regions in North America. The survey was conducted from June to September 2007. The study was approved by the Institutional Committee on Research Involving Human Subjects at the University of Pennsylvania.

\section{Survey content and administration}

The authors developed a list of the 50 most significant abdominal diagnoses, to be as complete as possible while allowing respondents to participate in a careful and unrushed manner. The survey was drafted by the authors and piloted by 5 practising emergency medicine faculty members to assess for readability and clarity of survey questions. The survey was modified to address deficiencies identified by the pilot group. The final format of the survey consisted of the following prompt, followed by the list of 50 diagnoses found in Table 1 :

You are evaluating a stable patient with acute abdominal pain in the emergency department. Consider the following final diagnoses. In each case, if the diagnosis is actually the cause of the patient's pain, please place into 1 of the following 3 categories: 1) unacceptable not to diagnose on the first visit; 2) although optimal to diagnose on first visit, if follow-up is assured within the next 2-7 days, failure to diagnose would not be expected to have serious adverse consequences; 3 ) if not diagnosed during the first visit, unlikely to cause long-term risk to patient provided the patient has follow-up within the next 1-2 months.

Participants were asked to consider each diagnosis in isolation, assume the patient to be without significant comorbidities or underlying illness, and to not consider the concomitant need for intravenous hydration, pain control or observation as a reason for choosing "unacceptable not to diagnose in the ED."

A Web-based survey tool (SurveyMonkey.com) was developed in which the list of diagnoses was associated with the choice of 1 of the 3 categories described above and sent to the study population with an email invitation to participate. Survey participants were informed that participation was voluntary and all identifying information would be kept confidential. Nonresponders were sent a follow-up survey invitation with a link.

\section{Outcome measure and data analysis}

Survey results were downloaded into an Excel spreadsheet 
(Microsoft Excel 2003, Microsoft Corp.). Our main outcome was a set of conditions considered by majority opinion to be "unacceptable" not to diagnose during the ED visit. We defined majority opinion a priori as agreement by more than $85 \%$ of our participants. Survey data were summarized using standard descriptive statistical analysis.

\section{RESULTS}

We identified 69 emergency physicians as recognized authorities in abdominal pain and emergency medicine research and invited them to participate in our survey. Thirty physicians ( $43 \%$ ) completed the entire survey. They were from the following geographic areas: 8 of 17 (47\%) from northeast United States, 6 of 15 (40\%) from southern United States, 11 of 22 (50\%) from midwest United States, 5 of 13 (38\%) from western United States and 0 of $2(0 \%)$ from Canada.
The survey results in their entirety are presented in Table 1. Of 50 total diagnoses, 16 were categorized as "unacceptable not to diagnose in the ED" with greater than $85 \%$ agreement (Table 2), and 12 were categorized as "acceptable not to diagnose in the ED" provided the patient had outpatient follow-up either in 2-7 days or 1-2 months with greater than $85 \%$ agreement (Table 3).

\section{DISCUSSION}

Abdominal pain remains the single most common reason for patients to visit the ED. Although most etiologies of abdominal pain are nonspecific or benign, emergency physicians must be able to promptly identify and treat those patients with serious, life-threatening diseases. Unfortunately, there is a paucity of evidence to support a clinical guideline or decision rule for evaluating undifferentiated abdominal pain, partly because

Table 1. Responses of 30 emergency physicians on the categorization of 50 diagnoses of abdominal pain (part 1 of 2)

\begin{tabular}{|c|c|c|c|c|}
\hline \multirow[b]{2}{*}{ Diagnosis } & \multicolumn{4}{|c|}{ Category; no. (\%) } \\
\hline & \multicolumn{2}{|c|}{$\begin{array}{l}\text { Unacceptable not to } \\
\text { diagnose in ED }\end{array}$} & $\begin{array}{l}\text { Acceptable not to } \\
\text { diagnose in ED with } \\
\text { follow-up in 2-7 d }\end{array}$ & $\begin{array}{l}\text { Acceptable not to } \\
\text { diagnose in ED with } \\
\text { follow-up in 1-2 mo }\end{array}$ \\
\hline \multicolumn{5}{|l|}{ Bowel } \\
\hline Gastritis & 0 & & $9(30.0)$ & $21(70.0)$ \\
\hline Gastroesophageal reflux disease & 0 & & $6(20.0)$ & $24(80.0)$ \\
\hline Peptic ulcer disease & 1 & (3.3) & 19 (63.3) & $10(33.3)$ \\
\hline lleus & 15 & $(50.0)$ & $15(50.0)$ & 0 \\
\hline Perforated viscus & 30 & $(100.0)$ & 0 & 0 \\
\hline Partial small bowel obstruction & 21 & $(70.0)$ & $9(30.0)$ & 0 \\
\hline Small bowel obstruction & 29 & $(96.7)$ & 1 (3.3) & 0 \\
\hline Colonic obstruction & 29 & $(96.7)$ & 1 (3.3) & 0 \\
\hline Nonperforated diverticulitis & 6 & $(20.0)$ & $23(76.7)$ & (3.3) \\
\hline Perforated diverticulitis with abscess & 27 & $(90.0)$ & $3(10.0)$ & 0 \\
\hline Colitis or regional ileitis with abscess or fistula & 25 & (83.3) & $5(16.7)$ & 0 \\
\hline Appendicitis, perforated with abscess & 29 & $(96.7)$ & $1 \quad(3.3)$ & 0 \\
\hline Appendicitis, no perforation & 20 & $(66.7)$ & 10 (33.3) & 0 \\
\hline \multicolumn{5}{|l|}{ Hepatobiliary } \\
\hline Acute cholecystitis & 29 & $(96.7)$ & $1 \quad$ (3.3) & 0 \\
\hline Chronic cholecystitis & 3 & $(10.0)$ & 25 (83.3) & $2 \quad(6.7)$ \\
\hline Symptomatic cholelithiasis without cholecystitis & 3 & $(10.0)$ & $18(60.0)$ & $9(30.0)$ \\
\hline Cirrhosis & 0 & & 13 (43.3) & $17(56.7)$ \\
\hline $\begin{array}{l}\text { Acute hepatitis without known coagulopathy or } \\
\text { encephalopathy }\end{array}$ & 7 & $(23.3)$ & $21(70.0)$ & $2(6.7)$ \\
\hline Acute hepatitis with coagulopathy or encephalopathy & 26 & $(86.7)$ & 4 (13.3) & 0 \\
\hline Spontaneous bacterial peritonitis & 26 & $(86.7)$ & 4 (13.3) & 0 \\
\hline Liver abscess & 22 & (73.3) & $8(26.7)$ & 0 \\
\hline Acute pancreatitis & 25 & (83.3) & $5(16.7)$ & 0 \\
\hline Pancreatic pseudocyst without acute pancreatitis & 5 & $(16.7)$ & $22(73.3)$ & $3(10.0)$ \\
\hline Acute exacerbation of chronic pancreatitis & 12 & $(40.0)$ & $16(53.3)$ & $2 \quad(6.7)$ \\
\hline
\end{tabular}


there is no clear definition of "clinically important" diagnoses or outcomes. We attempted to establish a set of diagnoses considered by expert opinion to be "unacceptable not to diagnose" during an initial ED visit, with the hope that they might be used as outcomes in future research on abdominal pain.

Survey choices " 2 " and " 3 " are often equivalent in the practice of emergency medicine: many patients who are instructed to get urgent follow-up in 2-7 days do not or cannot make appointments within this time frame, and many of those get no follow-up evaluation at all unless they return to the ED. This converts the 3 survey options into a binary proposition on clinical grounds: diagnoses are either "1" (unacceptable not to diagnose in the ED) or " $2 / 3$ " (acceptable not to diagnose in ED provided the patient has follow-up). More than $85 \%$ of our experts identified 16 abdominal pain conditions that were unacceptable not to diagnose during the initial ED visit. There were an additional $12 \mathrm{di}-$ agnoses determined by greater than $85 \%$ of our experts as acceptable if unrecognized during the current ED visit provided the patient had follow-up.

A prior study to derive a clinical guideline for the assessment of nonspecific abdominal pain created a list of 22 diagnoses that called for urgent intervention. ${ }^{8}$ The authors defined "urgent intervention" by consensus

Table 1. Responses of 30 emergency physicians on the categorization of 50 diagnoses of abdominal pain (part 2 of 2 )

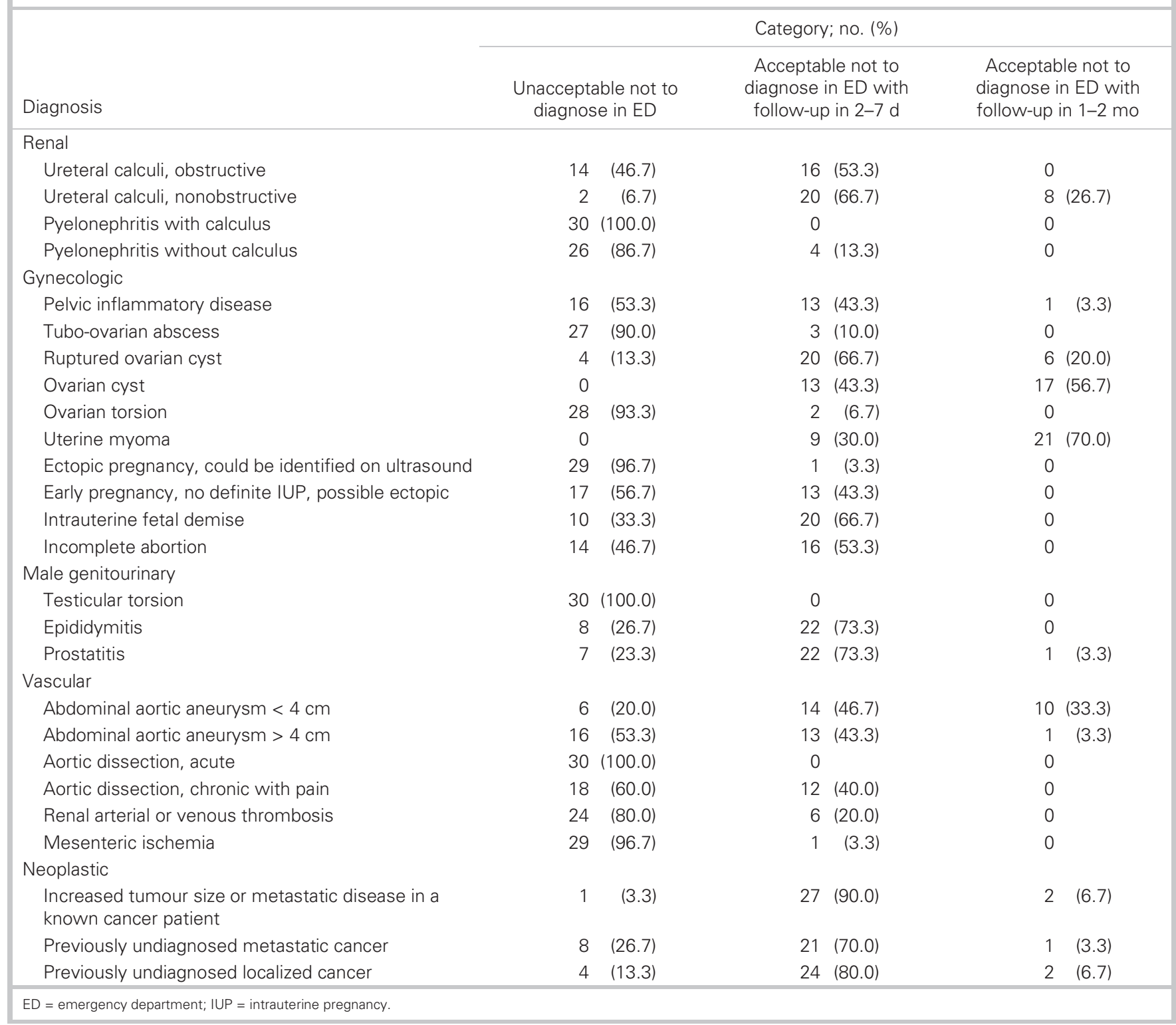


opinion of a panel of 4 board-certified emergency physicians and 1 board-certified general surgeon who were not associated with the study. Only half of our derivation of clinically important diagnoses is similar to theirs, including aortic dissection, bowel obstruction, cholecystitis, hepatitis (acute fulminant), mesenteric ischemia, perforated viscus, pyelonephritis, spontaneous bacterial peritonitis, tubo-ovarian abscess and appendicitis and diverticulitis (although only with perforation in our study). In contrast to their outcomes, our list of emergency diagnoses excludes nonperforated diverticulitis, colitis/regional ileitis, liver abscess, cholelithiasis, renal vascular thrombosis, ruptured ovarian cyst and newly diagnosed neoplasm.

Our study identifies a set of abdominal pain conditions as clinically important to diagnose during the initial ED visit. Our objective was to use the consensus opinion of a group of expert emergency physicians to derive this set of emergency diagnoses to be used as clinically significant outcomes for research purposes. With the difficulties experienced by many patients in complying with discharge plans for follow-up (especially the socio-economically disadvantaged group that uses the

\begin{tabular}{|c|c|}
\hline Diagnosis & Agreement, \% \\
\hline \multicolumn{2}{|l|}{ Bowel } \\
\hline Perforated viscus & 100.0 \\
\hline Small bowel obstruction & 96.7 \\
\hline Colonic obstruction & 96.7 \\
\hline Perforated diverticulitis with abscess & 90.0 \\
\hline Appendicitis, perforated with abscess & 96.7 \\
\hline \multicolumn{2}{|l|}{ Hepatobiliary } \\
\hline Acute cholecystitis & 96.7 \\
\hline $\begin{array}{l}\text { Acute hepatitis with coagulopathy or } \\
\text { encephalopathy }\end{array}$ & 86.7 \\
\hline Spontaneous bacterial peritonitis & 86.7 \\
\hline \multicolumn{2}{|l|}{ Renal } \\
\hline Pyelonephritis with calculus & 100.0 \\
\hline Pyelonephritis without calculus & 86.7 \\
\hline \multicolumn{2}{|l|}{ Gynecologic } \\
\hline Tubo-ovarian abscess & 90.0 \\
\hline Ovarian torsion & 93.3 \\
\hline $\begin{array}{l}\text { Ectopic pregnancy, could be identified on } \\
\text { ultrasound }\end{array}$ & 96.7 \\
\hline \multicolumn{2}{|l|}{ Male genitourinary } \\
\hline Testicular torsion & 100.0 \\
\hline \multicolumn{2}{|l|}{ Vascular } \\
\hline Aortic dissection, acute & 100.0 \\
\hline Mesenteric ischemia & 96.7 \\
\hline
\end{tabular}

ED because they lack access to outpatient care), many practising emergency physicians believe that there is an overriding imperative to identify not only the immediately life-threatening conditions, but also the subacute diagnoses (e.g., metastatic cancer, ovarian cyst) before a patient's discharge from the ED. Various individual patient factors may also lead to the appropriate discharge of some patients with conditions that are clinical emergencies and the appropriate admission of patients without immediately life-threatening conditions. The conditions identified in our study may be used as "clinically significant" outcomes for abdominal pain research and are not meant to be applied to clinical practice standards or used as the standard of care in the emergency evaluation of acute abdominal pain.

\section{Limitations}

There are several important limitations that must be addressed. First, our study was designed to categorize the urgency of various conditions for research purposes, for which the details of individual patients are not taken into account as they are in clinical practice. As a result, our data should not be applied to clinical practice standards and do not represent the standard of care. The number of identified authorities in abdominal pain was relatively small. Owing to the absence of scientifically

\begin{tabular}{lc|}
$\begin{array}{l}\text { Table 3. Abdominal pain diagnoses considered by more than } \\
\text { 85\% of respondents to be acceptable not to diagnose in the } \\
\text { emergency department provided patient had follow-up }\end{array}$ \\
\hline Diagnosis & Agreement, \% \\
\hline Bowel & 100.0 \\
Gastritis & 100.0 \\
Gastroesophageal reflux disease & 96.7 \\
Peptic ulcer disease & \\
Hepatobiliary & 90.0 \\
Chronic cholecystitis & \\
Symptomatic cholelithiasis without & 90.0 \\
cholecystitis & 100.0 \\
Cirrhosis & \\
Renal & 86.7 \\
Ureteral calculi, nonobstructive & \\
Gynecologic & 86.7 \\
Ruptured ovarian cyst & 100.0 \\
Ovarian cyst & 100.0 \\
Uterine myoma & \\
Neoplastic & \\
Increased tumour size or metastatic & 96.7 \\
disease in a known cancer patient & \\
Previously undiagnosed localized cancer & \\
\end{tabular}


validated criteria for determining expertise in abdominal pain, our survey could not control for bias in the selection of "experts." We also did not control for representation of all geographic regions or practice settings of the survey group. We recognize that our response rate of $43 \%$ was less than optimal; however, on review, our respondents were representative of the original survey group both with respect to region and the selection criteria by which they had been identified as potential experts.

We did not specify the extent of ED workup before diagnosis. For example, the $13 \%$ of experts who felt that it was unacceptable not to diagnose localized cancer may have based that opinion on the assumption that the hypothetical patient in the survey had not undergone CT. It is hard to imagine that they would consider this misdiagnosis unacceptable if a patient had had a negative CT scan, because the diagnosis of these conditions requires colonoscopy, dilation and curettage, or laparoscopy, all of which are not available in the ED.

\section{CONCLUSION}

Our study identifies a set of abdominal pain conditions considered to be clinically important to identify during the initial ED visit. We believe that these results could be useful as clinically significant outcomes for future research about the evaluation and management of abdominal pain. We do not intend our results to be used as standards of clinical care, because circumstances are likely to determine appropriate management on a case-by-case basis.

Competing interests: None declared.

\section{REFERENCES}

1. Pitts SR, Niska RW, Xu J, et al. National Hospital Ambulatory Medical Care Survey: 2006 emergency department summary. Natl Health Stat Report 2008;(7):1-38.

2. Nagurney JT, Brown DF, Chang Y, et al. Use of diagnostic testing in the emergency department for patients presenting with non-traumatic abdominal pain. 7 Emerg Med 2003;25:363-71.

3. Clinical policy: critical issues for the initial evaluation and management of patients presenting with a chief complaint of nontraumatic acute abdominal pain. Ann Emerg Med 2000; 36:406-15.

4. Hollander JE, Blomkalns AL, Brogan GX, et al. Standardized reporting guidelines for studies evaluating risk stratification of emergency department patients with potential acute coronary syndromes. Ann Emerg Med 2004;44:589-98.

5. Cannon CP, Battler A, Brindis RG, et al. American College of Cardiology key data elements and definitions for measuring the clinical management and outcomes of patients with acute coronary syndromes. A report of the American College of Cardiology Task Force on Clinical Data Standards (Acute Coronary Syndromes Writing Committee). 7 Am Coll Cardiol 2001;38:2114-30

6. Stiell IG, Greenberg GH, Wells GA, et al. Derivation of a decision rule for the use of radiography in acute knee injuries. Ann Emerg Med 1995;26:405-13.

7. Stiell IG, Wells GA, Vandemheen KL, et al. The Canadian C-spine Rule for radiography in alert and stable trauma patients. JAMA 2001;286:1841-8.

8. Gerhardt RT, Nelson BK, Keenan S, et al. Derivation of a clinical guideline for the assessment of nonspecific abdominal pain: the Guideline for Abdominal Pain in the ED Setting (GAPEDS) Phase 1 Study. Am J Emerg Med 2005;23:709-17.

Correspondence to: Dr. Angela Mills, Department of Emergency Medicine, University of Pennsylvania, 3400 Spruce St., Philadelphia PA 19104; millsa@uphs.upenn.edu 